\title{
COVID-19 Preventive Practices among Bus Station Workers in Ethiopia
}

\author{
Mebrahtu Eyasu, ${ }^{1 *}$ Yoseph Worku, ${ }^{2}$ Berhan Ababaw,${ }^{3}$ and Yifru Berhan ${ }^{4}$ \\ ${ }^{1}$ Saint Paul's Hospital Millennium Medical College, Department of Pharmacology, Addis Ababa, Ethiopia; ${ }^{2}$ Saint Paul's Hospital Millennium \\ Medical College, Department of Public Health, Addis Ababa, Ethiopia; ${ }^{3}$ Saint Paul's Hospital Millennium Medical College, Department of \\ Biochemistry, Addis Ababa, Ethiopia; ${ }^{4}$ Saint Paul's Hospital Millennium Medical College, Department of Obstetrics and Gynecology, Addis \\ Ababa, Ethiopia
}

\begin{abstract}
As of May 19, 2021, Ethiopia was among the five African countries most affected by COVID-19. A crosssectional design was used to assess the level of knowledge, perceptions, and practices of bus station workers about COVID-19 between August 25 and September 17, 2020. Face-to-face interviewer-administered questionnaires were used. To identify the factors associated with the dependent variables, simple and multiple binary logistic regression analyses were used. A $P$ value $<0.05$ was considered significant. Data were analyzed using SPSS version 20 software. In this study, 427 workers from three bus stations participated. Approximately $84.5 \%, 84.8 \%$, and $81.3 \%$ of the workers had good knowledge, positive perceptions, and good practices, respectively. Multivariable logistic regression analysis showed that workers with a monthly income of 3,001 to 4,000 birr were about four times more likely to have poor knowledge compared with higher income workers. Those workers with poor knowledge were 2.4 times, and security workers were 3.7 times, more likely to have poor practices compared with workers with good knowledge and drivers, respectively. In conclusion, workers used in security and those who had poor knowledge regarding COVID-19 failed to exhibit effective preventative practices against the virus.
\end{abstract}

\section{INTRODUCTION}

The human coronavirus first reared its ugly head more than five decades ago. ${ }^{1}$ In the past, the virus emerged in the form of Middle East respiratory syndrome and severe acute respiratory syndrome. ${ }^{2,3}$ The newly identified human coronavirus is named COVID-19, and this outbreak originated in Wuhan City, China, in late December 2019. By April 30, 2020 , most countries in the world were suffering the effects of COVID-19, some of which were already burdened by prevailing humanitarian crises. ${ }^{4}$ By May 19, 2021, COVID-19 had spread throughout the entire world, with more than 164 million confirmed cases and more than $3,420,532$ deaths attributed to it. ${ }^{5}$

COVID-19 has a high transmission rate with an unclear mechanism, but is spread primarily via respiratory droplets, aerosols, and, to a lesser degree, from contaminated objects. $^{6-9}$ Disease symptoms include fever, dry cough, fatigue, myalgia, and dyspnea. Severe cases present as an acute respiratory distress syndrome-like picture, with septic shock, intractable metabolic acidosis, and coagulation dysfunction. ${ }^{10,11}$ An occupation with a high COVID-19 risk of transmission is bus station workers, including bus drivers and cashiers. ${ }^{12}$

The WHO has provided guidance for the prevention and treatment of COVID-19. In addition, countries' health ministries have also provided guidelines. Adherence to these guidelines may be dependent on the level of knowledge, attitudes, and practices among populations. ${ }^{13-16}$ In outbreaks, panic or ignorance regarding the spread of infectious diseases may complicate attempts to prevent the spread of the disease. ${ }^{16-20}$ The rapid spread and mortality of COVID-19 created excessive anxiety among some individuals, ${ }^{21}$ especially those who remained unaffected. ${ }^{22}$

In Africa, the high levels of poverty, poorly developed health systems, and the population density of urban areas

*Address correspondence to Mebrahtu Eyasu, Department of Pharmacology, Saint Paul's Hospital Millennium Medical College, Addis Ababa, Ethiopia. E-mail: wedidellameb@gmail.com portended dire predictions about the virus. Although the jury remains out, it is speculated that a warmer climate, a youthful population, and former experiences of fighting infectious diseases has spared Africa the severest consequences of the pandemic seen on most other continents. ${ }^{23}$

In Addis Ababa, Ethiopia, despite the deaths caused by COVID-19, some inhabitants showed little adherence to the preventive measures promulgated by the government of Ethiopia. COVID-19 could spread at long-distance bus stations, where workers have direct contact with passengers who typically sit in close proximity on long-distance trips $(\geq 270 \mathrm{~km})$. We thought an assessment of the level of knowledge, perceptions, and the preventive practices of longdistance bus station workers about COVID-19 might be revealing.

\section{METHODS}

Study design, period, and setting. A cross-sectional study design was conducted between August 25 and September 17,2020, after 4 months of a state of emergency and social distancing. In Ethiopia, between August 25 and September 25, the total number of confirmed cases and deaths increased from 43,688 to 66,913 and from 709 to 1,060 , respectively. ${ }^{24}$ Our study was conducted at three longdistance bus stations (in Asko, Autobustera, and Lamberet) in Addis Ababa, Ethiopia. During the pandemic, 600 workers were active at these three stations.

Participants. Included in the study were workers 18 years of age or older who managed buses that traveled $\geq 270 \mathrm{~km}$. The minimum required sample size (425 participants) was obtained using the single-population proportion formula, using a $50 \%$ proportion and a margin of error of $5 \%$. After the Federal Ministry of Health at St. Paul's Hospital Millennium Medical College, Research Directorate Office, Addis Ababa, Ethiopia, grant call announcement, an application letter together with our research proposal was submitted by e-mail to the Research Directorate Office of the College for competition. Within 10 days, the assigned grant committee of the Research Directorate Office of the college screened 
and announced the proposal was one of the grant winner proposals. Furthermore, the directorate notified the institutional review board (IRB) of St. Paul's Hospital Millennium Medical College of the submission, which submitted to a strict review process. The IRB evaluated and approved the proposal. Subsequently, the study was conducted in the bus stations after obtaining ethical clearance from the IRB and a support letter from the Research Directorate Office. During the data collection period, to decrease the chance of contracting COVID-19 during face-to-face interviews, preventive safety measures against COVID-19 were adhered to. All participants gave their informed consent before participation. For all participants, ethical issues were strictly observed.

Sampling technique. In our study, participants were recruited from the three long-distance bus stations using the opportunistic sampling technique. During the COVID-19 crisis, the workers were drivers $(n=127)$, driver supporters $(n=57)$, loaders/uploaders $(n=29)$, cashiers $(n=59)$, guards (gate; $n=35)$, simirits $(n=47)$, security personnel $(n=29)$, cleaners $(n=30)$, and others (daily laborers, gardeners, and administrative staff; $n=20$ ).

Variables, definitions, and outcomes. The dependent variables were knowledge (good or poor), perception (negative or positive), and practice (good or poor). The questions used to assess the sociodemographic characteristics, knowledge, perception, and practice regarding COVID-19 were the independent variables. Knowledge was the awareness of COVID-19. Perception was the state of preparedness when confronted with COVID-19. Practice was the act of taking preventive measures regarding the virus. Knowledge, perceptions, and practices were measured by calculating the mean score of 15 items (knowledge), seven items (perception), and 11 items (practices). The variables were categorized as good knowledge, positive perceptions, and good practices if participants scored the mean score or more of the correctly answered questions for each category, or as poor knowledge, negative perceptions, and poor practices if participants scored less than the mean score of the correctly answered questions. ${ }^{25}$

The Supplemental questionnaire was modified and adapted from published articles. ${ }^{15,26-29}$ Knowledge questions were answered as true or false, or "I don't know." The perception and practice questions had only a true or false option. Correct answers were coded as 1 point, incorrect, 0 point. Before analysis, negatively worded items which had correct answers other than the "true" option correct answers were scored reversely. A "simirit" is an individual used at long-distance bus stations whose primary responsibility includes scheduling departure times and setting regional bus routes.

Data collection and quality management. Data collectors were trained in the study objectives, data collection methods, quality of data, and communication skills. The prestructured questionnaire was pretested 2 weeks prior to the actual data collection on $5 \%$ of the sample size from Zenebe Work, a long-distance bus station in Addis Ababa. Based on the feedback from the questionnaire, modifications were made. The supervisors' reviewed data daily for inconsistencies and completeness. All in all, data collection was done through face-to-face interviews.

Statistical analysis. Data were coded, entered, cleaned, and analyzed using SPSS version 20 software (SPSS Inc.,
Chicago, IL). Descriptive analyses (frequency, percentage, and mean) were computed. To determine the level of knowledge, perceptions, and preventive practices of the participants, the means of the corrected answers were calculated. To identify factors associated with the dependent variables, simple and multiple binary logistic regression analyses were conducted. In the simple binary logistic regression, all factors with a $P$ value $<0.20$ were considered candidates for the multiple binary logistic regression. In all statistical tests, a $P$ value $<0.05$ was significant.

\section{RESULTS}

Sociodemographic characteristics. A total of 427 workers participated in this study. The mean age $( \pm S D)$ was $35.88 \pm 10.80$ years (range, 19-78 years). Approximately 127 workers (29.7\%) were drivers, 59 (13.8\%) were cashiers, and $51(11.9 \%)$ were driver supporters. The workers were predominantly male $(n=388,90.9 \%)$ with an age range of 25 to 44 years $(n=293,68.6 \%)$, married $(n=262,61.4 \%)$, had completed secondary school $(n=231,54.1 \%)$, were Orthodox Christians $(n=366,85.7 \%)$, and were city residents $(n=394,92.4 \%)$. Majority of the workers, 182 $(42.6 \%)$, were from one of the bus stations (Autobustera) (Table 1).

Long-distance bus station workers' knowledge. The workers' average knowledge score was $11.69 \pm 1.38$ points (range, 3-15 points). Four hundred thirteen workers (96.7\%) were aware of the most common clinical symptoms, 204 (47.8\%) could distinguish the virus from the common cold/flu, and 354 (82.9\%) believed there was no effective cure. Approximately 383 workers (89.7\%) knew that COVID-19 was spread via respiratory droplets of an infected patient. However, 318 workers (74.5\%) stated that asymptomatic transmission was possible.

Most workers avoided crowded places ( $n=396,92.7 \%)$, wore masks ( $n=399,93.4 \%$ ), and understood that contact with an infected person would result in immediate isolation $(n=419,98.1 \%)$ with a quarantine time of 14 days $(n=410$, $96 \%$ ), and COVID-19 patients would remain in the treatment center until discharge $(n=423,99.1 \%)$. About 339 workers $(79.4 \%)$ reported that COVID-19 was airborne, that eating or touching wild animals would not result in transmission ( $n=118,27.6 \%$ ), that isolation and treatment effectively reduced transmission ( $n=421,98.6 \%)$, and that children and young adults should take preventive measures $(n=347$, $81.3 \%$ ). Overall, good knowledge was demonstrated by 361 workers (84.5\%).

Preventive practices regarding COVID-19. The mean score for practices was $10 \pm 1.20$ points. Most workers selfreported that they had not recently visited any crowded places $(n=306,71.7 \%)$; that they wore face masks ( $n=413,96.7 \%)$; that they stopped shaking hands $(n=416$, $97.4 \%$ ); that they frequently washed their hands with water and soap ( $n=421,98.6 \%)$; that they avoided touching their eyes, nose, and mouth before handwashing ( $n=407$, $95.3 \%)$; that they discarded used masks in dust bins ( $n=414,97 \%$ ), and that they followed government instructions $(n=420,98.4 \%)$. After work, however, 95 workers $(22.2 \%)$ did not stay home, $52(12.2 \%)$ did not avoid close proximity (within $2 \mathrm{~m}$ ), and $26(6.1 \%)$-during coughing and/ or sneezing-did not use a tissue or cough into their elbow. 
TABLE 1

Sociodemographic characteristics

\begin{tabular}{|c|c|}
\hline Characteristic & $n(\%)$ \\
\hline \multicolumn{2}{|l|}{ Gender } \\
\hline Male & $388(90.9)$ \\
\hline Female & $39(9.1)$ \\
\hline \multicolumn{2}{|l|}{ Age group (y) } \\
\hline $18-24$ & $53(12.4)$ \\
\hline $25-34$ & $153(35.8)$ \\
\hline $35-44$ & $140(32.8)$ \\
\hline $45-54$ & $50(11.7)$ \\
\hline$\geq 55$ & $31(7.3)$ \\
\hline \multicolumn{2}{|l|}{ Education } \\
\hline Illiterate & $11(2.6)$ \\
\hline Read and write & $4(0.9)$ \\
\hline Elementary & $128(30)$ \\
\hline Secondary & $231(54.1)$ \\
\hline College & $53(12.4)$ \\
\hline \multicolumn{2}{|l|}{ Religion } \\
\hline Orthodox & $366(85.7)$ \\
\hline Muslim & $26(6.1)$ \\
\hline Protestant & $33(7.7)$ \\
\hline Catholic & $1(0.2)$ \\
\hline Other & $1(0.2)$ \\
\hline \multicolumn{2}{|l|}{ Marital status } \\
\hline Single & $147(34.4)$ \\
\hline Married & $262(61.4)$ \\
\hline Divorced & $10(2.3)$ \\
\hline Widowed & $7(1.6)$ \\
\hline Separated & $1(0.2)$ \\
\hline \multicolumn{2}{|l|}{ Residency } \\
\hline Addis Ababa & $394(92.3)$ \\
\hline Other ${ }^{*}$ & $33(7.7)$ \\
\hline \multicolumn{2}{|c|}{ Monthly income (birr) $\dagger$} \\
\hline$\leq 1,000$ & $73(17.1)$ \\
\hline $1,001-2,000$ & $153(35.8)$ \\
\hline $2,001-3,000$ & $76(17.8)$ \\
\hline $3,001-4,000$ & $35(8.2)$ \\
\hline$\geq 4,001$ & $90(21.1)$ \\
\hline \multicolumn{2}{|l|}{ Job } \\
\hline Driver & $127(27.9)$ \\
\hline Driver supporter & 51 (11.9) \\
\hline Loader/uploader & $29(6.8)$ \\
\hline Cashier & $59(13.8)$ \\
\hline Guard (gate) & $35(8.2)$ \\
\hline Simirit & $47(11)$ \\
\hline Security & $29(6.8)$ \\
\hline Cleaner & $30(7)$ \\
\hline Otherf & $20(4.7)$ \\
\hline \multicolumn{2}{|c|}{ Long-distance bus station } \\
\hline Asko & $145(34)$ \\
\hline Autobustera & $182(42.6)$ \\
\hline Lamberet & $100(23.4)$ \\
\hline
\end{tabular}

The majority of the workers $(n=347,81.3 \%)$ demonstrated good practices.

Long-distance bus station workers' perceptions. The mean perception score was $5.5 \pm 1.07$ points. Most of the workers received health education about COVID-19 $(n=361,84.5 \%)$, agreed that COVID-19 would be controlled successfully $(n=360,84.3 \%)$, had confidence that Ethiopia could win the battle against COVID-19 $(n=389,91.1 \%)$, believed the Ethiopian government handled the crisis very well ( $n=376,88.1 \%)$, and thought that COVID-19-infected individuals might be stigmatized $(n=270,63.2 \%)$.

In response to statements posed to the participants, the following self-reported results were found: 127 workers
$(29.7 \%)$ reported they would get infected despite practicing the safety measures, 157 workers (36.8\%) believed COVID19 patients would be stigmatized by those who knew their health status, and, if infected, most workers $(n=412$, 96.5\%) thought there were risks for themselves and their families. Most of the workers had positive perceptions $(n=362,84.8 \%)$.

Factors associated with knowledge, practices, and perceptions. Multivariable logistic regression analysis showed that workers with a monthly income of 3,001 to 4,000 birr were about four times more likely to have poor knowledge compared with higher income workers (adjusted odds ratio [AOR], 3.929; $95 \% \mathrm{Cl}, 1.326-11.640$ ). Married workers were $47.3 \%$ less likely to have poor COVID-19 knowledge compared with single workers (AOR, 0.527; 95\% Cl, 0.286-0.972) (Table 2).

Workers with poor knowledge were 2.4 times more likely to have poor practices compared with workers with good knowledge (AOR, 2.383; 95\% Cl, 1.252-4.538), and security workers were 3.7 times more likely to have poor practices compared with drivers (AOR, 3.721; 95\% Cl, 1.098-12.609). In addition, workers with secondary-level education were $59.2 \%$ less likely to have poor COVID-19 practices compared with workers with college-level education (AOR, 0.408; 95\% Cl, 0.187-0.891) (Table 3).

Workers with elementary and secondary education were 64.4\% (AOR, 0.356; 95\%, Cl, 0.141-0.899) and 57.0\% (AOR, 0.430; $95 \% \mathrm{Cl}, 0.194-0.954$ ) less likely to have poor perceptions compared with those with college-level education, respectively (Table 4).

\section{DISCUSSION}

In this study, multiple binary logistic regression analyses showed that workers with secondary education had a significant association with poor practices. This finding is similar to studies in Ethiopia ${ }^{30}$ and India. ${ }^{31}$ A study in Iran $^{32}$ and Pakistan ${ }^{33}$ concluded that a higher level of education was associated with high preventive practices. In general, education is one of the contributing factors that affects healthy actions. ${ }^{34}$ However, those with lower education might have a challenge in seeking information on how to practice preventive safety measures against COVID-19 infection. Therefore, because of their lower educational status, workers might have poor practices with regard to COVID-19 prevention. ${ }^{35}$

There was a strong and significant association between working as security personnel and poor practices. This is supported by the results of a study conducted in Uganda. ${ }^{27}$ In our study, more than $80 \%$ of all workers exhibited good practices, which is similar to the findings in $\mathrm{Uganda}^{27}$ and Vietnam. ${ }^{36}$ Workers with poor knowledge about COVID-19 were significantly associated with poor practices. This finding is consistent with reports from Ethiopia ${ }^{30}$ and Vietnam. ${ }^{36}$ Considering such practices, the investigators recommended that these populations be targeted for teaching about safety measures and how to apply them. ${ }^{2,6}$ Furthermore, this finding is in line with the association of good knowledge about COVID-19. ${ }^{27}$

Workers in our study with monthly incomes between 3,001 and 4,000 birr were significantly associated with poor knowledge compared with those with higher incomes. This result is similar to other studies. ${ }^{30,37,38}$ Higher income 
TABLE 2

Multivariable logistic regression of workers' knowledge about COVID-19 in Addis Ababa, Ethiopia

\begin{tabular}{|c|c|c|c|c|}
\hline \multirow[b]{2}{*}{ Predictor } & \multicolumn{2}{|c|}{ Knowledge level } & \multirow[b]{2}{*}{ COR $(95 \% \mathrm{Cl}), P$ value } & \multirow[b]{2}{*}{ AOR $(95 \%, \mathrm{Cl}), P$ value } \\
\hline & Poor, n (\%) & Good, n (\%) & & \\
\hline \multicolumn{5}{|l|}{ Marital status } \\
\hline Single & $34(23.1)$ & $113(76.9)$ & 1 & 1 \\
\hline Married & $31(11.8)$ & $231(88.2)$ & 0.446 (0.261-0.762), 0.003 & 0.527 (0.286 - 0.972), 0.040 \\
\hline Others ${ }^{\star}$ & $1(5.6)$ & $17(94.4)$ & $0.196(0.025-1.523)$ & $0.227(0.027-1.876)$ \\
\hline \multicolumn{5}{|l|}{ Residency } \\
\hline Addis Ababa & $58(14.7)$ & $336(85.3)$ & 1 & 1 \\
\hline Other & $8(24.2)$ & $25(75.8)$ & $1.854(0.797-4.309)$ & $2.451(0.983-6.112), 0.055$ \\
\hline \multicolumn{5}{|l|}{ Monthly income (birr) } \\
\hline$\geq 4,001$ & $8(8.9)$ & $82(91.1)$ & 1 & 1 \\
\hline$\leq 1,000$ & $11(15.1)$ & $62(84.9)$ & $1.819(0.690-4.791)$ & $0.769(0.166-3.559)$ \\
\hline $1,001-2,000$ & $28(18.3)$ & $125(81.7)$ & $2.296(0.998-5.285)$ & $1.345(0.342-5.297)$ \\
\hline $2,001-3,000$ & $9(11.8)$ & $67(88.2)$ & 1.377 (0.504-3.764) & $1.034(0.278-3.843)$ \\
\hline $3,001-4,000$ & $10(28.6)$ & $25(71.4)$ & 4.100 (1.461-11.506), 0.007 & 3.929 (1.326-11.640), 0.014 \\
\hline \multicolumn{5}{|r|}{ 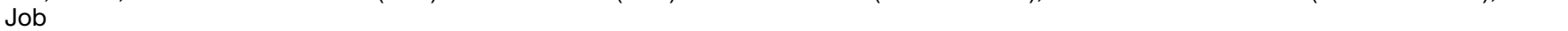 } \\
\hline Driver & $17(13.4)$ & $110(86.6)$ & 1 & 1 \\
\hline Driver supporter & 9 (17.6) & $42(82.4)$ & $1.387(0.574-3.352)$ & $1.371(0.338-5.568)$ \\
\hline Loader/uploader & $3(10.3)$ & $26(89.7)$ & $0.747(0.204-2.739)$ & $1.056(0.219-5.088)$ \\
\hline Cashier & $16(27.1)$ & $43(72.9)$ & 2.408 (1.117-5.191), 0.025 & $2.374(0.642-8.783)$ \\
\hline Guard (gate) & $8(22.9)$ & $27(77.1)$ & 1.917 (0.749-4.907) & $2.782(0.633-12.219)$ \\
\hline Simirit & 5 (10.6) & $42(89.4)$ & $0.770(0.267-2.220)$ & $0.666(0.192-2.311)$ \\
\hline Security & $4(13.8)$ & $25(86.2)$ & 1.035 (0.3203.344) & $1.501(0.329-6.844)$ \\
\hline Cleaner & $3(10)$ & $27(90)$ & $0.719(0.196-2.632)$ & $0.807(0.148-4.414)$ \\
\hline Other & $1(5)$ & $19(95)$ & $0.341(0.043-2.712)$ & $0.479(0.053-4.311)$ \\
\hline
\end{tabular}

$\mathrm{AOR}=$ adjusted odds ratio; $\mathrm{COR}$ = crude odds ratio; $\mathrm{Cl}$ = confidence interval; $\mathrm{n}(\%)$ is number (percentage).

${ }^{*}$ Divorced, Widowed, and Separated.

participants were associated with better understanding and safer practices. ${ }^{15}$ Economic status appeared to be a central factor with regard to maintaining recommended health practices. $^{39}$

Married workers were also less likely to have poor knowledge about COVID-19 compared with those workers who were single. This finding is similar to an earlier report from Ethiopia. ${ }^{40}$ However, a previous study found that ${ }^{41}$ unmarried people were more likely to have good knowledge of COVID-19.

Our study revealed that a large number of workers had positive perceptions about COVID-19, similar to a report from Nigeria, ${ }^{42}$ and more than those found in a study from Uganda. ${ }^{27}$ Although there is no published evidence for comparing this finding, workers with elementary and secondary education were significantly associated and less likely to

TABLE 3

Multivariable logistic regression of workers' preventive practices for COVID-19 in Addis Ababa, Ethiopia

\begin{tabular}{|c|c|c|c|c|}
\hline \multirow[b]{2}{*}{ Predictor } & \multicolumn{2}{|c|}{ Practice level } & \multirow[b]{2}{*}{ COR $(95 \% \mathrm{Cl}), P$ value } & \multirow[b]{2}{*}{ AOR $(95 \% \mathrm{Cl}), P$ value } \\
\hline & Poor, n (\%) & Good, n (\%) & & \\
\hline \multicolumn{5}{|l|}{ Education } \\
\hline College & 19 (35.8) & $34(64.2)$ & 1 & 1 \\
\hline Informal & $1(6.7)$ & $14(93.3)$ & $0.128(0.016-1.049)$ & $0.194(0.020-1.892)$ \\
\hline Elementary & $26(20.3)$ & $102(79.7)$ & $0.456(0.225-0.925), 0.030$ & $0.554(0.237-1.291)$ \\
\hline Secondary & $34(14.7)$ & $197(85.3)$ & 0.309 (0.158-0.603), 0.001 & 0.408 (0.187-0.891), 0.024 \\
\hline \multicolumn{5}{|l|}{ Monthly income } \\
\hline$\geq 4,001$ & $13(14.4)$ & $77(85.6)$ & 1 & 1 \\
\hline$\leq 1,000$ & $11(15.1)$ & $62(84.9)$ & $1.051(0.440-2.508)$ & $0.639(0.176-2.318)$ \\
\hline $1,001-2,000$ & 28 (18.3) & $125(81.7)$ & $1.327(0.648-2.716)$ & $0.828(0.268-2.560)$ \\
\hline $2,001-3,000$ & $21(27.6)$ & $55(72.4)$ & $2.262(1.044-4.901), 0.039$ & $1.376(0.489-3.873)$ \\
\hline $3,001-4,000$ & 7 (20) & $28(80)$ & 1.481 (0.536-4.088) & 1.125 (0.377-3.359) \\
\hline \multicolumn{5}{|l|}{ Knowledge level } \\
\hline Good & $60(16.6)$ & $301(83.4)$ & 1 & 1 \\
\hline Poor & $20(30.3)$ & $46(69.7)$ & 2.181 (1.205-3.949), 0.01 & 2.383 (1.252-4.538), 0.008 \\
\hline \multicolumn{5}{|r|}{ 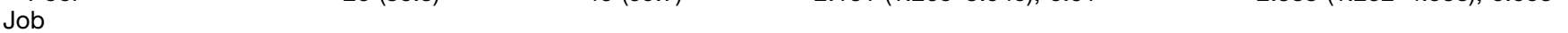 } \\
\hline Driver & $16(12.6)$ & $111(87.4)$ & 1 & 1 \\
\hline Driver supporter & 11 (21.6) & $40(78.4)$ & $1.908(0.817-4.457)$ & 2.419 (0.714-8.203) \\
\hline Loader/uploader & $6(20.7)$ & $23(79.3)$ & $1.810(0.640-5.121)$ & $2.002(0.558-7.186)$ \\
\hline Cashier & 9 (15.3) & $50(84.7)$ & $1.249(0.517-3.017)$ & $1.299(0.383-4.412)$ \\
\hline Guard (gate) & $6(17.1)$ & 29 (82.9) & $1.435(0.516-3.994)$ & $1.585(0.385-6.521)$ \\
\hline Simirit & $12(25.5)$ & $35(74.5)$ & 2.379 (1.027-5.506), 0.043 & $1.721(0.578-5.125)$ \\
\hline Security & 11 (37.9) & $18(62.1)$ & 4.240 (1.698-10.586), 0.002 & 3.721 (1.098-12.609), 0.035 \\
\hline Cleaner & $3(10)$ & $27(90)$ & 0.771 (0.209-2.837) & $1.166(0.225-6.054)$ \\
\hline Other & $6(30)$ & $14(70)$ & 2.973 (0.999-8.848), 0.05 & $2.825(0.757-10.546)$ \\
\hline
\end{tabular}


TABLE 4

Multivariable logistic regression of workers' perception about COVID-19 in Addis Ababa, Ethiopia

\begin{tabular}{|c|c|c|c|c|}
\hline \multirow[b]{2}{*}{ Predictor } & \multicolumn{2}{|c|}{ Perception level } & \multirow[b]{2}{*}{ COR $(95 \% \mathrm{Cl}), P$ value } & \multirow[b]{2}{*}{ AOR $(95 \% \mathrm{Cl}), P$ value } \\
\hline & Negative, n (\%) & Positive, $n(\%)$ & & \\
\hline \multicolumn{5}{|l|}{ Education } \\
\hline College & $14(26.4)$ & 39 (73.6) & 1 & 1 \\
\hline Informal & 2 (13.3) & $13(86.7)$ & $0.429(0.086-2.142)$ & $0.362(0.059-2.212)$ \\
\hline Elementary & $15(11.7)$ & $113(88.3)$ & 0.370 (0.164-0.835), 0.017 & $0.356(0.141-0.899), 0.029$ \\
\hline Secondary & $34(14.7)$ & 197 (85.3) & 0.481 (0.236-0.979), 0.043 & $0.430(0.194-0.954), 0.038$ \\
\hline \multicolumn{5}{|l|}{ Marital status } \\
\hline Single & $30(20.4)$ & 117 (79.6) & 1 & 1 \\
\hline Married & $33(12.6)$ & $229(87.4)$ & $0.562(0.327-0.967), 0.037$ & $0.598(0.322-1.109)$ \\
\hline Other & $2(11.1)$ & $16(88.9)$ & $0.488(0.106-2.237)$ & $0.610(0.127-2.934)$ \\
\hline \multicolumn{5}{|l|}{ Job } \\
\hline Driver & $15(11.8)$ & $112(88.2)$ & 1 & 1 \\
\hline Driver supporter & $6(11.8)$ & 45 (88.2) & $0.996(0.363-2.728)$ & $0.853(0.296-2.459)$ \\
\hline Loader/uploader & $6(20.7)$ & $23(79.3)$ & $1.948(0.683-5.553)$ & $2.095(0.717-6.125)$ \\
\hline Cashier & $14(23.7)$ & 45 (76.3) & 2.323 (1.037-5.203), 0.040 & $1.836(0.776-4.348)$ \\
\hline Guard (gate) & $6(17.1)$ & $29(82.9)$ & $1.545(0.551-4.332)$ & $1.346(0.451-4.013)$ \\
\hline Simirit & $9(19.1)$ & 38 (80.9) & $1.768(0.716-4.370)$ & $1.069(0.395-2.889)$ \\
\hline Security & $4(13.8)$ & 25 (86.2) & $1.195(0.365-3.908)$ & $1.094(0.321-3.732)$ \\
\hline Cleaner & $4(13.3)$ & $26(86.7)$ & $1.149(0.352-3.748)$ & $1.311(0.353-4.874)$ \\
\hline Other & 1 (5) & 19 (95) & $0.393(0.049-3.151)$ & $0.275(0.032-2.323)$ \\
\hline
\end{tabular}

have a poor perception of COVID-19. In our study, nearly $85 \%$ of workers had good knowledge. Studies in Tanzania ${ }^{28}$ and Uganda $^{27}$ reported similar findings.

Most of the workers in our study had prior health education. More than $90 \%$ knew the main clinical symptoms of COVID-19, similar to findings in a study from Nepal, ${ }^{43}$ but more than the number found a study from Ethiopia. ${ }^{26} \mathrm{~A}$ large number of workers in our study felt confident that Ethiopia could win the battle against COVID-19. This sentiment matches the results of previous studies. ${ }^{15,28,37}$

Nearly three quarters of the workers in our study knew that older people and/or people with chronic illnesses were at greater risk of developing a severe form of COVID-19. This has been supported by previous studies. ${ }^{26,29,44,45}$ A small portion of the workers still perceived that COVID-19 infected only the elderly, which is similar to reports from Nepal and Pakistan. ${ }^{43,46}$

Our study also revealed that almost three quarters of workers knew about asymptomatic transmission of COVID19 , which is inconsistent with previous studies in Ethiopia ${ }^{26}$ and Saudi Arabia. ${ }^{47}$ This discrepancy might be a result of the limited sample size and the length of time since the outbreak of the virus. More than half the workers understood the reason for social distancing and the time periods of quarantine, treatment, and discharge. These findings are similar to previous studies. ${ }^{43,47,48}$

Almost all the workers in our study self-reported to wearing masks. This report is consistent with a study conducted in China. ${ }^{15}$ Earlier studies, however, revealed less mask adherence. ${ }^{36,37,42,46,49-51}$ Reasons could be participants' beliefs about COVID-19 prevalence, the amount of time since the outbreak, or sporadic public service education. Also, changing guidelines disseminated by the $\mathrm{WHO}^{52}$ and the Centers for Disease Control and Prevention could be influencing factors. ${ }^{53}$

A large number of workers self-reported coughing and/or sneezing into their elbows/masks. In addition, they did not touch their eyes, nose, or mouth before handwashing or hand sanitizing. These findings are similar to those from
Ethiopia, ${ }^{40}$ the Philippines, ${ }^{54}$ Pakistan, ${ }^{50}$ and Nigeria. ${ }^{42}$ In the Indian study, compliance was found to be less. ${ }^{49}$

One study limitation included workers' attempts to give socially acceptable, correct responses to be more accurateparticularly for the perception and practice questions. ${ }^{55}$ To mitigate this, data collectors stressed that actual status reflecting responses was critical.

In conclusion, clearly, some workers exhibited poor COVID19 preventative practices. Because the nature of their work engenders frequent and close proximity to the general public, the impact of this failure cannot be underestimated. Reformatting and redirecting training protocols to address the personal and/or emotional perspectives of these workers would likely result in better compliance. Presentations must be delivered by a knowledgeable, engaged, and enthusiastic training team. Last, a schedule of monitoring must be initiated to verify the program's validity and/or deficiencies accurately.

Received November 2, 2020. Accepted for publication October 7, 2021.

Published online November 5, 2021.

Note: Supplemental questionnaire in English appears at www.ajtmh. org. Supplemental questionnaire in Amharic can be found at https:// data.mendeley.com/datasets/cd58z6wfz5/1.

Acknowledgments: We thank participating volunteers and the bus station administrators for their kind assistance during the data collection period. We also thank Mark Stambovsky for his assistance in helping us edit the manuscript. The American Society of Tropical Medicine and Hygiene has waived the Open Access fee for this article due to the ongoing COVID-19 pandemic and has assisted with publication expenses.

Financial support: This work was supported by a grant from the Federal Ministry of Health, Saint Paul's Hospital Millennium Medical College, Addis Ababa, Ethiopia.

Authors' addresses: Mebrahtu Eyasu, Saint Paul's Hospital Millennium Medical College, Department of Pharmacology, Addis Ababa, Ethiopia, E-mail: wedidellameb@gmail.com. Yoseph Worku, Saint Paul's Hospital Millennium Medical College, Department of Public Health, Addis Ababa, Ethiopia, E-mail: worku_yoseph@yahoo.com. Berhan Ababaw, Saint Paul's Hospital Millennium Medical College, Department 
of Biochemistry, Addis Ababa, Ethiopia, E-mail: berhan766@gmail. com. Yifru Berhan, Saint Paul's Hospital Millennium Medical College, Department of Obstetrics and Gynecology, Addis Ababa, Ethiopia, E-mail: yifruberhanm@gmail.com.

This is an open-access article distributed under the terms of the Creative Commons Attribution (CC-BY) License, which permits unrestricted use, distribution, and reproduction in any medium, provided the original author and source are credited.

\section{REFERENCES}

1. European Centre for Disease Prevention and Control, 2020. Cluster of Pneumonia Cases Caused by a Novel Coronavirus, Wuhan, China. Stockholm, Sweden: European Centre for Disease Prevention and Control.

2. Huang $\mathrm{C}$ et al., 2020. Clinical features of patients infected with 2019 novel coronavirus in Wuhan, China. Lancet 395: 497506.

3. World Health Organization, 2020. Coronavirus Disease Outbreak: Rights, Roles and Responsibilities of Health Workers, Including Key Considerations for Occupational Safety. Geneva, Switzerland: WHO.

4. The Committee for the Coordination of Statistical Activities, 2020. How COVID-19 Is Changing the World: A Statistical Perspective. Available at: https://unstats.un.org/unsd/ccsa/ documents/covid19-report-ccsa_vol3.pdf. Accessed October 20, 2021.

5. Worldometer, 2021. Coronavirus. Available at: https://www. worldometers.info/coronavirus/country/ethiopia/. Accessed October 25, 2021.

6. Adhikari SP et al., 2020. A literature review of 2019 novel coronavirus during the early outbreak period: epidemiology, causes, clinical manifestation and diagnosis, prevention and control. Infect Dis Poverty 9: 1-29.

7. Sohrabi C, Alsafi Z, O'Neill N, Khan M, Kerwan A, Al-Jabir A, losifidis C, Agha R, 2020. WHO declares global emergency: a review of the 2019 novel coronavirus. Int J Surg 76: 71-76.

8. Lai CC, Shih TP, Ko WC, Tang HJ, Hsueh PR, 2020. Severe acute respiratory syndrome coronavirus 2 and COVID-19: the epidemic and the challenges. Int J Antimicrob Agents 55: 1-9.

9. Guan WJ et al., 2020. Clinical characteristics of coronavirus disease 2019 in China. N Engl J Med 382: 1708-1720.

10. National Health Commission of the People's Republic of China, 2020. A Protocol for Community Prevention and Control of COVID-19 Infected Pneumonia (Trial Version). Available at: http://www.nhc.gov.cn/jkj/s3577/202001/dd1e502534004a8d 88b6. Accessed October 15, 2020.

11. Chen $\mathrm{N}$ et al., 2020. Epidemiological and clinical characteristics of 99 cases of 2019 novel coronavirus pneumonia in Wuhan, China: a descriptive study. Lancet 395: 507-513.

12. World Economic Forum, 2020. These Are the Occupations with the Highest COVID-19 Risk. Available at: https://www. weforum.org/agenda/2020/04/occupations-highest-covid19risk/. Accessed January 28, 2021.

13. Ajilore K, Atakiti I, Onyenankeya K, 2017. College students' knowledge, attitudes and adherence to public service announcements on Ebola in Nigeria: suggestions for improving future Ebola prevention education programmes. Health Educ J 76: 648-660.

14. Tachfouti N, Slama K, Berraho M, Nejjari C, 2012. The impact of knowledge and attitudes on adherence to tuberculosis treatment: a case-control study in a Moroccan region. Pan Afr Med J 12: 52.

15. Zhong BL, Luo W, Li HM, Zhang QQ, Liu XG, Li WT, Li Y, 2020. Knowledge, attitudes, and practices towards COVID-19 among Chinese residents during the rapid rise period of the COVID-19 outbreak: a quick online cross-sectional survey. Int J Biol Sci 16: 1745-1752.1

16. Taber KS, 2018. The use of Cronbach's alpha when developing and reporting research instruments in science education. Res Sci Educ 48: 1273-1296.
17. Zhou X, Xiu C, Chu Q, 2004. Prevention and treatment knowledge and attitudes towards SARS of urban residents in Qingdao. Prev Med Trib 10: 407-408.

18. Liu Z, Gao H, Zhang S, 2004. Prevention and treatment knowledge towards SARS of urban population in Jinan. Prev Med Trib 10: 659-660.

19. Person B et al., 2004. Fear and stigma: the epidemic within the SARS outbreak. Emerg Infect Dis 10: 358-363.

20. Tao N, 2003. An analysis on reasons of SARS-induced psychological panic among students. J Anhui Inst Educ 21: 78-79.

21. Roy D, Tripathy S, Kar SK, Sharma N, Verma SK, Kaushal V, 2020. Study of knowledge, attitude, anxiety and perceived mental healthcare need in Indian population during COVID-19 pandemic. Asian J Psychiatr 51: 1-7.

22. Ilesanmi O, Alele FO, 2016. Knowledge, attitude and perception of Ebola virus disease among secondary school students in Ondo State, Nigeria. PLoS Curr. 8: 1-12.

23. Africa Center for Strategic Studies, 2020. Mapping Risk Factors for the Spread of COVID-19 in Africa. Available at: https:// africacenter.org/spotlight/mapping-risk-factors-spread-covid19-africa/. Accessed May 27, 2020.

24. Worldometer, 2020. Coronavirus. Available at: https://www. worldometers.info/coronavirus/country/ethiopia/. Accessed October 7, 2020.

25. Kassahun CW, Mekonen AG, 2017. Knowledge, attitude, practices and their associated factors towards diabetes mellitus among nondiabetes community members of Bale Zone administrative towns, south east Ethiopia: a cross-sectional study. PLoS One 12: e0170.

26. Kebede Y, Yitayih Y, Birhanu Z, Mekonen S, Ambelu A, 2020. Knowledge, perceptions and preventive practices towards COVID-19 early in the outbreak among Jimma University Medical Center visitors, southwest Ethiopia. PLoS One 15: e0233744.

27. Ssebuufu R, Sikakulya F, Binezero SM, Wasingya L, Nganza SK, Ibrahim B, Kyamanywa P, 2020. Awareness, knowledge, attitude and practice towards measures for prevention of the spread of COVID-19 in the Ugandans: a nationwide online cross-sectional survey. Front. in Public Health 8: 1-9.

28. Rugarabamu S, Ibrahim M, Byanaku A, 2020. Knowledge, Attitudes, and Practices (KAP) Towards COVID-19: A Quick Online Cross-sectional Survey among Tanzanian Residents. Available at: https://www.medrxiv.org/content/10.1101/ 2020.04.26.20080820v2. Accessed October 30, 2021.

29. Abdelhafiz AS, Mohammed Z, Ibrahim ME, Ziady HH, Alorabi M, Ayyad M, Sultan EA, 2020. Knowledge, perceptions, and attitude of Egyptians towards the novel coronavirus disease (COVID-19). J Community Health 45: 881-890.

30. Akalu Y, Ayelign B, Molla MD, 2020. Knowledge, attitude and practice towards COVID-19 among chronic disease patients at Addis Zemen Hospital, Northwest Ethiopia. Infect Drug Resist 13: 1949-1960.

31. Amalakanti S, Raman Arepalli KV, Koppolu RK, 2020. Gender and occupation predict coronavirus disease 2019 knowledge, attitude and practices of a cohort of a south Indian state population. Indian J Med Microbiol 38: 144-151.

32. Erfani A, Shahriarirad R, Ranjbar K, Mirahmadizadeh A, Moghadami M, 2020. Knowledge, attitude and practice toward the novel coronavirus (COVID-19) outbreak: a population-based survey in Iran. Bull world Health Organ. Available at: https:// www.who.int/bulletin/online_first/20-256651.pdf. Accessed June 20, 2020.

33. Saqlain M, Ahmed A, Nabi L, Gulzar A, Naz S, Munir MM, Ahmed Z, Kamran S, 2021. Public's knowledge and practices regarding COVID-19: a cross-sectional survey from Pakistan. Front Public Health 9: 1-11.

34. Park CL, Cho D, Moore PJ, 2018. How does education lead to healthier behaviours? Testing the mediational roles of perceived control, health literacy and social support. Psychol Health 33: 1416-1429.

35. Gebremeskel F III, Teklay E, Gebrehaweria M, 2021. Preventive practice and associated factors toward coronavirus disease 19 in Adigrat Town, northern Ethiopia: community-based cross-sectional study. Infect Drug Resist 14: 2379-2386. 
36. Huynh G, Nguyen MQ, Tran TT, Nguyen VT, Nguyen TV, Do THT, Nguyen PHN, Phan THY, Vu TT, Nguyen TNH, 2020. Knowledge, attitude, and practices regarding COVID-19 among chronic illness patients at outpatient departments in Ho Chi Minh City, Vietnam. Risk Manag Healthc Policy 13: 1571-1578.

37. Azlan AA, Hamzah MR, Sern TJ, Ayub SH, Mohamad E, 2020. Public knowledge, attitudes and practices towards COVID19: a cross-sectional study in Malaysia. PLoS One 15: e0233668.

38. Wolf MS et al., 2020. Awareness, attitudes, and actions related to COVID-19 among adults with chronic conditions at the onset of the US outbreak. Ann Intern Med 173: 100-109.

39. Mantwill S, Monestel-Umaña S, Schulz PJ, 2015. The relationship between health literacy and health disparities: a systematic review. PLoS One 10: e0145455.

40. Nigussie TF, Azmach NN, 2020. Knowledge, attitude and practice towards COVID-19 among Arba Minch town residents, southern Ethiopia. GSJ 8: 1283-1307.

41. Mechessa DF, Ejeta F, Abebe L, Henok A, Nigussie T, Kebede O, Mamo Y, 2020. Community's knowledge of COVID-19 and its associated factors in Mizan-Aman Town, southwest Ethiopia. Int J Gen Med 13: 507-513.

42. Reuben RC, Danladi MM, Saleh DA, Ejembi PE, 2020. Knowledge, attitudes and practices towards COVID-19: an epidemiological survey in north-central Nigeria. $J$ Commun Health 46: 457-470.

43. Singh DR, Sunuwar DR, Karki K, Ghimire S, Shrestha N, 2020. Knowledge and perception towards universal safety precautions during early phase of the COVID-19 outbreak in Nepal. $J$ Commun Health 45: 1116-1122.

44. Li LQ, Huang T, Wang YQ, Wang ZP, Liang $Y$, Huang TB, Zhang HY, Sun W, Wang Y, 2020. COVID-19 patients' clinical characteristics, discharge rate, and fatality rate of meta-analysis. J Med Virol 92: 577-583.

45. Sahu KK, Mishra AK, Lal A, 2020. Comprehensive update on current outbreak of novel coronavirus infection (2019-nCoV). Ann Transl Med 8: 393.
46. Saleem MK, Lal A, Sanaullah A, Sheikh M, Saaed S, Ahmed N, 2020. Knowledge, attitude, and practice towards COVID-19 among general population of Karachi South: a cross-sectional survey. J Dow Univ Health Sci 14: 77-82.

47. Almofada SK, Alherbisch RJ, Almuhraj NA, Almeshary BN, Alrabiah B, Al Saffan A, Baseer MA, 2020. Knowledge, attitudes, and practices toward COVID-19 in a Saudi Arabian population: a cross-sectional study. Cureus 12: e8905.

48. Hager E, Odetokun IA, Bolarinwa O, Zainab A, Okechukwu O, Al-Mustapha Al, 2020. Knowledge, attitude, and perceptions towards the 2019 coronavirus pandemic: a bi-national survey in Africa. PLoS One 15: e0236918.

49. Dkhar SA, Quansar R, Saleem SM, Khan SM, 2020. Knowledge, attitude, and practices related to COVID-19 pandemic among social media users in $\mathrm{J} \& \mathrm{~K}$, India. Indian $\mathrm{J}$ Public Health 64: S205-S210.

50. Wajahat M, Ahmed H, Sherwani SK, 2020. Knowledge, attitude and practice towards COVID-19 among general public of Islamabad, Pakistan. Int J Basic Med Sci Pharmacy 9: 50-56.

51. Hezima A, Aljafari A, Aljafari A, Mohammad A, Adel I, 2020. Knowledge, attitudes, and practices of Sudanese residents towards COVID-19. East Mediterr Health J 26: 646-651.

52. World Health Organization, 2020. Coronavirus Disease Advice for the Public: When and How to Use Masks. Available at: https://www.who.int/emergencies/diseases/novel-coronavirus2019/advice-for-public/when-and-how-to-use-masks. Accessed September 25, 2020.

53. Centers for Disease Control and Prevention, 2020. Recommendation Regarding the Use of Cloth Face Coverings, Especially in Areas of Significant Community-Based Transmission. Available at: https://www.cdc.gov/coronavirus/2019-ncov/preventgetting-sick/cloth-face-cover.htm. Accessed October 4, 2020.

54. Lau LL, Hung N, Go DJ, Ferma J, Choi M, Dodd W, Wei X, 2020. Knowledge, attitudes and practices of COVID-19 among income-poor households in the Philippines: a crosssectional study. J Glob Health 10: 1-11.

55. Van de Mortel TF, 2008. Faking it: social desirability response bias in self-report research. Aust J Adv Nurs 25: 40-48. 